\title{
Seizures and Hyponatremia Related to Ethcathinone and Methylone Poisoning
}

\author{
Cindy Boulanger-Gobeil • Maude St-Onge • \\ Martin Laliberté • Pierre L. Auger
}

Published online: 14 July 2011

(C) American College of Medical Toxicology 2011

\begin{abstract}
Introduction We report a case of ethcathinone and methylone poisoning with severe clinical toxicity. This is to our knowledge the first case reported in the medical toxicology literature.

Case Report A 22-year-old woman was brought to the emergency department following several episodes of tonicoclonic seizures, a few hours after ingesting "legal ecstasy". The patient needed intubation for recurrent seizures, and she was found to have severe hyponatremia $(120 \mathrm{mmol} / \mathrm{L})$ that was corrected with hypertonic saline. The patient's mental status improved rapidly, and she was extubated the day following her admission. However, she developed prolonged rhabdomyolysis (CK $34.537 \mathrm{U} / \mathrm{L}$ ) that required a 6-day hospitalisation.

Discussion The seizures and the hyponatremia may be explained by the MDMA-like characteristics of methylone that may induce inappropriate secretion of antidiuretic hormone mediated via the serotonin system. The combination of methylone and ethcathinone (both acting like
\end{abstract}

C. Boulanger-Gobeil $\cdot$ M. St-Onge

Université Laval,

Quebec, QC, Canada

M. Laliberté

McGill University,

Quebec, QC, Canada

P. L. Auger

Direction de la santé publique de Québec,

Quebec, QC, Canada

M. St-Onge $(\bowtie) \cdot M$. Laliberté

Quebec Poison Control Center,

1270 Chemin Sainte-Foy, 4e étage,

Québec, QC G1S 2M4, Canada

e-mail: egnomie@hotmail.com serotonin reuptake inhibitors) might have contributed to neurologic manifestations compatible with serotonin toxicity, although our patient never had autonomic instability. Our patient had a prolonged period of rhabdomyolysis which may also be explained by excessive serotonin activity resulting in an increased motor hyperactivity. The public has to be aware of this growing health problem. Clinicians must report future cases of toxicity related to the use of cathinone synthetic derivatives in order to increase our knowledge of these substances.

Keywords Ethcatinone $\cdot$ Methylone $\cdot$ Amphetamine . Poisoning $\cdot$ Mephedrone

\section{Introduction}

"Legal highs" are compounds that can be readily bought without legal restriction, even if some of these chemicals may be structurally related to illegal drugs of abuse [1]. There have been reports of toxicity with mephedrone but never with another cathinone derivative, ethcathinone [2]. We report a case of severe neurologic toxicity and hyponatremia related to recreational use of ethcathinone and methylone. A brief review of the literature will follow to put those facts into perspective and to discuss possible hypotheses explaining the patient evolution.

\section{Case Description}

A healthy 22-year-old $(60 \mathrm{~kg})$ Caucasian woman was brought to the emergency department following four episodes of vomiting and five episodes of tonicoclonic seizures lasting around $20 \mathrm{~s}$ each. The patient drinks 
approximately four alcoholic beverages per day and smokes marijuana approximately once a month. She had no significant medical history, and she was taking an oral contraceptive.

The evening before, she had visited a hemp shop looking to buy a cannabinoid substance for recreational purposes. The seller convinced her to try "legal ecstasy" (white powder diluted in water). She bought and ingested approximately the amount of a teabag of the product, with three alcoholic beverages, at around 11:00 p.m. Sometime after, she developed euphoria, agitation, sweating and intense thirst. She drank $3.5 \mathrm{~L}$ of water after the ingestion and had her first tonicoclonic seizure.

The patient was brought to the emergency department by ambulance $6 \mathrm{~h}$ post-ingestion. She was disoriented and confused with a Glasgow Coma Score of 11 on 15 (eye $=4$, verbal $=3$, motor $=4$ ). Blood pressure was $137 /$ 85 , heart rate was $83 / \mathrm{min}$, temperature was $35.9^{\circ} \mathrm{C}$ and oxygen saturation was $98 \%$. The initial physical exam revealed equally dilated and reactive pupils at $6 \mathrm{~mm}$, nystagmus, hyperreflexia, exhaustible clonus and bruxism. The rest of the physical exam was otherwise normal. Approximately $90 \mathrm{~min}$ after arrival, the patient presented another tonicoclonic seizure with quasi opisthotonos lasting $1 \mathrm{~min}$ and a half. After this episode, her saturation decreased to $66 \%$, and her level of consciousness deteriorated. She received lorazepam, $1 \mathrm{mg} I V$, to control the seizure. She was intubated with midazolam, $5 \mathrm{mg}$ IV; fentanyl, $100 \mu \mathrm{g}$ IV and succinycholine, $90 \mathrm{mg}$ IV. Her vitals remained stable throughout the procedure. Post-intubation, the patient was given a loading dose of $1 \mathrm{~g}$ of phenytoin IV. The sodium was found to be $120 \mathrm{mmol} / \mathrm{L}$ with an osmolarity of $253 \mathrm{mmol} / \mathrm{L}$ in her first laboratory results. To correct this hyponatremia, the patient received a $\mathrm{NaCl} 3 \%$ drip at $20 \mathrm{cc} / \mathrm{h}$. She was diagnosed with acute "ecstasy like" intoxication causing a SIADH exacerbated with potomania. The seizures were explained by the direct toxicity of the substance, plus the hyponatremia.

The patient's initial laboratory evaluation showed a compensated metabolic acidosis ( $\mathrm{pH} 7.37 / \mathrm{pCO}_{2}$ $31 \mathrm{mmHg} / \mathrm{pO}_{2} 84 \mathrm{mmHg} / \mathrm{HCO}_{3} 18 \mathrm{mmol} / \mathrm{L}$ ) with an anion gap of 15 , an elevation of creatine kinase (CK, $951 \mathrm{U} / \mathrm{L})$, a hypokalemia $(3.0 \mathrm{mmol} / \mathrm{L})$ with hypochloremia $(87 \mathrm{mmol} /$ $\mathrm{L})$, hypomagnesemia $(0.57 \mathrm{mmol} / \mathrm{L})$, hypophosphoremia $(0.77 \mathrm{mmol} / \mathrm{L})$, a total calcium of $2.20 \mathrm{mmol} / \mathrm{L}$, a blood glucose of $6.7 \mathrm{mmol} / \mathrm{L}$, a normal renal function and

Fig. 1 Chemical structure of methylone<smiles>CNC(C)C(=O)c1ccc2c(c1)OCO2</smiles>

Fig. 2 Chemical structure of ethcathinone

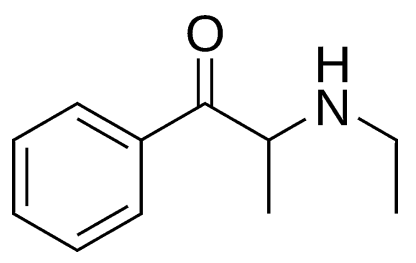

negative cardiac enzymes. The blood count was normal, except for a leucocytosis of $14.9 \times 10^{9} / \mathrm{L}$. Hepatic and pancreatic enzymes were normal, pregnancy test was negative, thyroid function tests were normal and random cortisol was normal. The ethanol level was $7.0 \mathrm{mmol} / \mathrm{L}$, and both acetaminophen and salicylates were negative. The ECG showed a normal sinus rhythm with normal QRS and QT intervals. CT scan of the head was normal. $\mathrm{NaCl} 3 \%$ was administered along with $120 \mathrm{cc} / \mathrm{h}$ of $\mathrm{NaCl} 0.9 \%$. The patient was sedated with midazolam $(5 \mathrm{mg} / \mathrm{h})$ and fentanyl $(100 \mu \mathrm{g} / \mathrm{h})$ and transferred to the Intensive Care Unit (ICU).

The infusions of $\mathrm{NaCl} 3 \%$ and $\mathrm{NaCl} 0.9 \%$ were continued in the ICU, but sedation was switched to propofol at a rate of $20-25 \mathrm{cc} / \mathrm{h}(10 \mathrm{mg} / \mathrm{ml})$. Upon arrival in the ICU, the urine output was around $30 \mathrm{cc} / \mathrm{h}$, and urine analysis showed blood and ketones at the macroscopic analysis, but no red cells on microscopy. Urine sodium was $158 \mathrm{mmol} / \mathrm{L}$, urine chloride was $136 \mathrm{mmol} / \mathrm{L}$ and urine osmolality was $476 \mathrm{mmol} / \mathrm{L}$. Around 11:00 a.m., $4 \mathrm{~h}$ after ICU admission, the patient presented an impressive increase in her urine output $(1,000-1,500 \mathrm{cc} / \mathrm{h})$. The $\mathrm{NaCl}$ $3 \%$ and $\mathrm{NaCl} 0.9 \%$ were stopped for $3 \mathrm{~h}$, and D5\% $1 / 2 \mathrm{NS}$ was started at $80 \mathrm{cc} / \mathrm{h}$. Serum electrolytes were monitored closely to control the rate of $\mathrm{Na}$ correction. The Na level went back to a normal level approximately $14 \mathrm{~h}$ after arrival.

The next day, the patient's level of consciousness had improved, and she was extubated without complications. $\mathrm{Na}$ was up at $136 \mathrm{mmol} / \mathrm{L}$, but $\mathrm{CK}$ rose at $2.087 \mathrm{U} / \mathrm{L}$ and then up to $34.537 \mathrm{U} / \mathrm{L}$ with myoglobinuria. $\mathrm{NaHCO}_{3}$ $50 \mathrm{mmol} / \mathrm{NaCl} 0.45 \%$ at $100 \mathrm{cc} / \mathrm{h}$ and $\mathrm{NaCl} 0.45 \%$ at $100 \mathrm{cc} / \mathrm{h}$ were started. The patient complained of diffuse myalgia. $\mathrm{CK}$ reached $36.648 \mathrm{U} / \mathrm{L}$ on the evening of the third day of the patient admission, who was hospitalised for an additional $72 \mathrm{~h}$ until the $\mathrm{CK}$ values normalized. There was no evidence of renal failure. On discharge, the patient was asymptomatic.

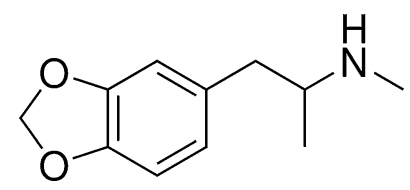

Fig. 3 Chemical structure of ecstasy (MDMA) 
With the patient's consent, the police, the provincial poison control centre and the Department of Public Health were contacted to investigate. The authorities subsequently seized the substance she was sold at the hemp shop. It was analysed by the Drug Analysis Service (Health Canada) by gas chromatography-flame ionisation detector and gas chromatography-mass spectrometry and confirmed by comparison with national reference standards. The results finally revealed that the substance was a mixture of methylone and ethcathinone, considered illegal in Canada, as all amphetamine derivatives. The population was made aware of the potential dangers of "legal highs".

\section{Discussion}

Methylone (2-methylamino-1-(3,4-methylenedioxyphenyl)propan-1-one, bk-MDMA) is a beta-keto designer drug (4-methyl-methcathinone). Methylone increases the concentration of monoamine neurotransmitters such as serotonin, dopamine and noradrenaline in the human synaptic cleft, through inhibition of plasma membrane monoamine reuptake transporters [3]. Methylone acts as a stimulant of the central nervous system and has some hallucinogenic effects. This substance was synthesized in 1996 as an anti-depressant and an anti-parkinsonian [4]. Its MDMA-like character was reported shortly after [5]. More recently, this drug has been identified as a new designer drug, more specifically in European markets. Methylone is marketed on the internet as a high-purity plant food, which can give false confidence to teenagers and young adults attracted to stimulants similar to ecstasy (Figs. 1, 2, 3) [3].

Ethcathinone 2-ethylamino-1-phenyl-propan-1-one (ethylpropion) is a metabolite of diethylcathinone (diethylpropion) that has been used as an anorectic agent by stimulating thermogenesis [6]. It is also a drug of the amphetamine [7] class and a chemical derivative of cathinone that is progressively entering the recreational drug market [8]. It mainly acts as a moderately potent noradrenaline releasing agent, with relatively weak inhibition of dopamine and serotonin reuptake. It is a stimulant drug with euphoric properties.

The seizures and the hyponatremia in our case may be explained by the MDMA-like character of methylone that could trigger inappropriate secretion of antidiuretic hormone mediated via the serotonin system. The hyponatremia, which can be explained by the pharmacological activity of the two molecules, was probably exacerbated by excessive water intake. The combination of methylone and ethcathinone, both amphetamine-like molecules, might have contributed to neurologic manifestations (agitation, confusion, nystagmus, clonus) and rhabdomyolysis, which are known manifestations of serotonin toxicity.

Brunt et al. [9] found that more than $50 \%$ of ecstasy tablets sold in the Netherlands in 2009 contained other substances. It seems obvious that several individuals unwittingly get exposed to "legal highs". Medical toxicologists must report future cases to increase our knowledge of this new recreational drugs' toxicity.

\section{References}

1. Gibbons S, Zloh M (2010) An analysis of the "legal high" mephedrone. Bioorg Med Chem Lett 20:4135-4139

2. Wood DM, Greene SL, Dargan PI (2011) Clinical pattern of toxicity associated with the novel synthetic cathinone mephedrone. Emerg Med J 28:280-282

3. Kamata HT, Shima N, Zaitsu K, Kamata T, Miki A, Nishikawa M, Katagi M, Tsuchihashi H (2006) Metabolism of the recently encountered designer drug, methylone, in humans and rats. Xenobiotica 36(8):709-723

4. Jacob P III, Shulgin AT (1996) Novel N-substituted-2-amino$3^{\prime}, 4^{\prime}$ methylene-dioxypropioophenones, International Application Published under the Patent Cooperation Treaty, 12 December 1996

5. Dal Cason TA, Young R, Glennon RA (1997) Cathinone: an investigation of several $\mathrm{N}$-alkyl and methylenedioxy-substituted analogs. Pharmacol Biochem Behav 58(4):1109-1116

6. Lang SS, Danforth E Jr, Lien EL (1983) Anorectic drugs which stimulate thermogenesis. Life Sci 33(13):1269-1275

7. Meyer MR, Wilhelm J, Peters FT, Maurer HH (2010) Beta-keto amphetamines: studies on the metabolism of the designer drug mephedrone and toxicological detection of mephedrone, butylone, and methylone in urine using gas chromatography-mass spectrometry. Anal Bioanal Chem 397(3):1225-1233

8. Wood DM, Davies S, Puchnarewicz M, Button J, Archer R, Ovaska H, Ramsey J, Lee T, Holt DW, Dargan PI (2010) Recreational use of mephedrone (4-methylmethcathinone, 4-MMC) with associated sympathomimethic toxicity. J Med Toxicol 6:327-330

9. Brunt TM, Poortman A, Niesink RJ, van den Brink W (2011) Instability of the ecstasy market and a new kid on the block: mephedrone. J Psychopharmacol. (in press) 